\title{
Refractory cardiogenic shock due to extensive anterior STEMI with covered left ventricular free wall rupture treated with awake VA-ECMO and LVAD as a double bridge to heart transplantation - collaboration of three cardiac centres
}

\author{
Jan Kacer ${ }^{\mathrm{a}}$, Michaela Lindovska ${ }^{\mathrm{a}}$, Roman Surovcik ${ }^{\mathrm{a}}$, Ivan Netuka ${ }^{\mathrm{b}, \mathrm{c}}$, Frantisek Mlejnsky ${ }^{\mathrm{c}}$, Tomas Grus ${ }^{\mathrm{c}}$, Jan Belohlavek ${ }^{\mathrm{d}}$
}

Aim. To highlight an optimal collaborative strategy of three different levels of specialized care cardiac centres.

Background. Refractory cardiogenic shock is a life-threatening condition. A myocardial recovery is not achieved in many cases despite all efforts and subsequently the heart transplantation remains an ultimate option. Thereby, the use of extracorporeal membrane oxygenation (ECMO) followed by a ventricular assist device in staged bridging provides an attractive approach.

Case report. We report on an optimal cooperation of $\mathrm{PCI}$ (percutaneous coronary intervention) centre with ELSO (extracorporeal life support organization) centre and transplant centre in a patient suffering from refractory cardiogenic shock due to acute myocardial infarction (RCSMI) complicated by left ventricle free wall rupture with pericardial tamponade. Conclusion. The interhospital collaboration can be essential in the context of patients with RCSMI. The use of ECMO enables safe interhospital transport and gains time for further diagnostic and therapeutic steps in such critically ill patients.

Key words: refractory cardiogenic shock in acute myocardial infarction, percutaneous coronary intervention, extracorporeal membrane oxygenation, left ventricle assist device

Received: April 9, 2015; Accepted with revision: September 10, 2015; Available online: October 23, 2015 http://dx.doi.org/10.5507/bp.2015.044

\author{
${ }^{a}$ Department of Cardiology, Bulovka Hospital, Prague, Czech Republic \\ ${ }^{b}$ Cardiovascular Surgery Department, IKEM, Prague \\ ${ }^{c}{ }^{\text {nd }}$ Department of Surgery, Cardiovascular Surgery, First Faculty of Medicine, Charles University in Prague and General University Hospital \\ in Prague \\ ${ }^{d} 2^{\text {nd }}$ Department of Medicine - Department of Cardiovascular Medicine, First Faculty of Medicine, Charles University in Prague and General \\ University Hospital in Prague \\ Corresponding author: Jan Kacer, e-mail:jankacer@icloud.com
}

\section{INTRODUCTION}

Cardiogenic shock as a complication of acute myocardial infarction (CSMI) is a life-threatening condition with high mortality. The last significant progress in the treatment of CSMI positively influencing the clinical outcome has been known for 15 years - early reperfusion of the infarct related coronary artery ${ }^{1}$. The management of pharmacological therapy in order to improve the circulation has its limitations. Therefore, mechanical circulatory support (MCS) is often initiated and is the last possible solution to prevent an inevitable death ${ }^{2}$. In many cases, the utilization of MCS in a treatment of refractory cardiogenic shock as a complication of myocardial infarction (RCSMI) does not stop by mere improvement of the circulation in the acute phase. In the context of RCSMI we can divide MCS into two consecutive procedures: 1) improving the circulation in the acute phase - a bridge to decision (BTD) and 2) the use of a long-term ventricle assist device (LVAD) as a bridge to transplant (BTT) $\left(\right.$ ref. $\left.^{3}\right)$. The implementation of the latter is in the majority of cases required to reach the final solution in patients with the inability to be weaned from short-term MCS, since it is very rare to use ECMO as a bridge to urgent heart transplantation (HTX) (ref. ${ }^{4)}$. We report a case of a patient suffering from this life-threatening condition requiring both short and long term MCS in order to reach a definitive solution.

\section{CASE REPORT}

A 62-year-old male with no significant previous medical history presented at the emergency department of a community hospital with chest pain that began $10 \mathrm{~h}$ earlier for the first time in his life. The pain was dull and non-radiating. Apart from this, the patient had no other complaints. After the diagnosis of acute coronary syndrome (ACS) with ST segment elevation was established, the patient was transferred to our PCI centre. He had been smoking forty to sixty cigarettes a day for more than thirty years. Upon examination, the patient was overweight with the body mass index of $28.09 \mathrm{~kg} / \mathrm{m} 2$ and appeared well. His blood pressure was $130 / 85 \mathrm{mmHg}$ and his pulse was $95 / \mathrm{min}$. An electrocardiogram showed a sinus rhythm at 95 beats per min, normal axis, $Q$ waves in leads I, VL, V1-V6, raised ST segments in leads I, VL, V3V6, depressed ST segments in lead III (Fig. 1). Laboratory 


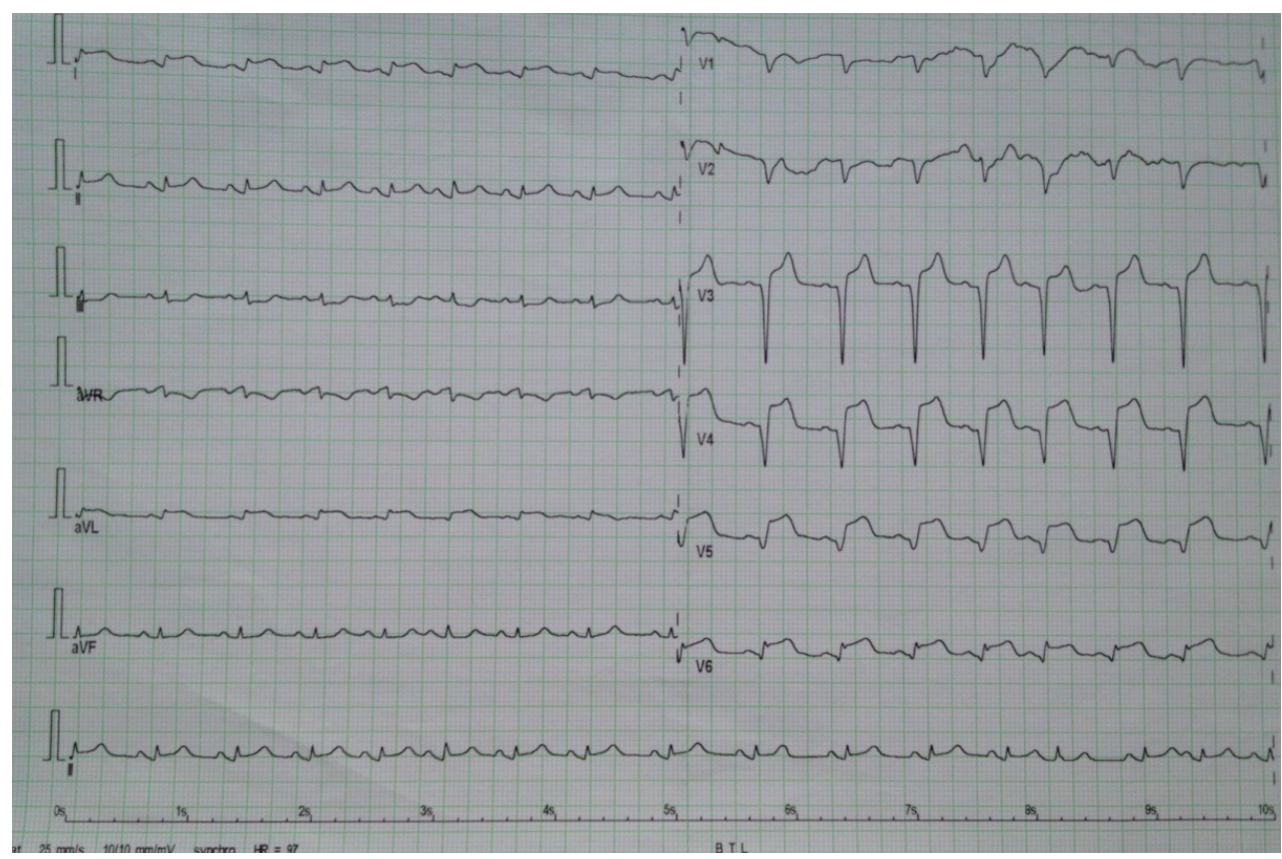

Fig. 1. 12-lead electrocardiogram in the patient with extensive anterior STEMI ( $11 \mathrm{~h}$ after onset of symptoms).

examination demonstrated raised cardiac enzymes levels, remaining laboratory tests were unremarkable (see Table 1). The patient was given aspirin and clopidogrel orally and heparin intravenously. Due to ST-elevation myocardial infarction (STEMI) with ongoing ischemia, the cardiac catheterization was carried out immediately with the first-medical-contact-to-balloon time of $60 \mathrm{~min}$ but with the total ischemic time (TIT) of $11 \mathrm{~h}$. Coronary angiography images showed total thrombotic occlusion of the proximal segment of left anterior descending coronary artery (LAD) (Fig. 2). Subsequently, percutaneous coronary intervention (PCI) was performed. The thrombus was removed by aspiration device and drug-eluting stent was deployed at the site of $90 \%$ stenosis. After PCI, the TIMI grade flow 2 was achieved in LAD. Considering the low consumption of contrast media, left ventriculography (LVG) was performed and it determined large dyskinesia of the left ventricle apex and akinesia of anterior wall with severely impaired left ventricle (LV) systolic function with the ejection fraction (EF) of $25 \%$ (Fig. 3). Transthoracic echocardiography (TTE) was consistent with LVG. Subsequently, however, despite the proper intravascular volume, the patient became hemodynamically unstable and inotropic (dobutamine) and vasopressor (norepinephrine) drug therapy was necessary to maintain mean arterial pressure (MAP) of 60 to $70 \mathrm{~mm} \mathrm{Hg}$. On the second day of hospitalization, despite the prior revascularization and the treatment with high-dose catecholamines, a multiple organ failure (MOF) began to develop due to low cardiac output owing to persisting severely impaired contractility of LV as demonstrated by a TTE. TTE also revealed pericardial effusion, which, however, did not show signs of pericardial tamponade (Fig. 4). The patient suffered from two episodes of short cardiac arrests caused by ventricular fibrillation promptly solved by defibrillations. The laboratory data revealed slightly elevated lactate, blood

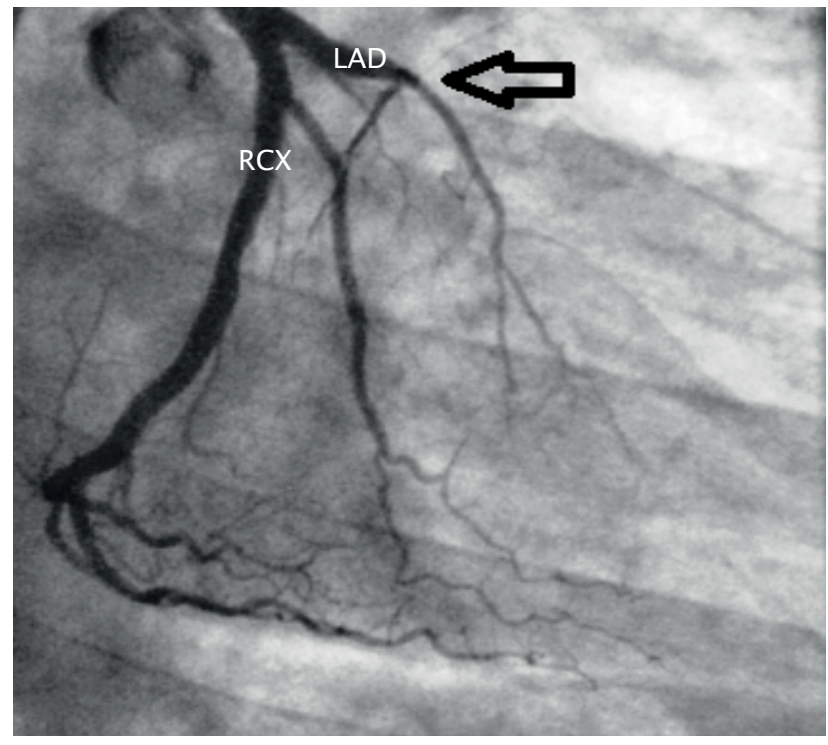

Fig. 2. Total thrombotic occlusion of proximal segment of left anterior descending coronary artery (see arrow).

LAD; left anterior descending coronary artery, RCX; circumflex artery

urea nitrogen and serum creatinine. Serum minerals were within the normal limits. A blood gas analysis showed mild metabolic acidosis. Cardiac enzymes were consistent with major myocardial injury, liver enzymes showed only mild elevation. Elevated levels of white blood cell count and C-reactive protein were presumably attributable to the systemic inflammatory response (see Table 1). Based on a deteriorating status, we decided to contact the Extracorporeal Life Support Organization (ELSO) centre to discuss the initiation of short term MCS using extracorporeal membrane oxygenation (ECMO). The mobile ECMO transport team composing of an interventional 

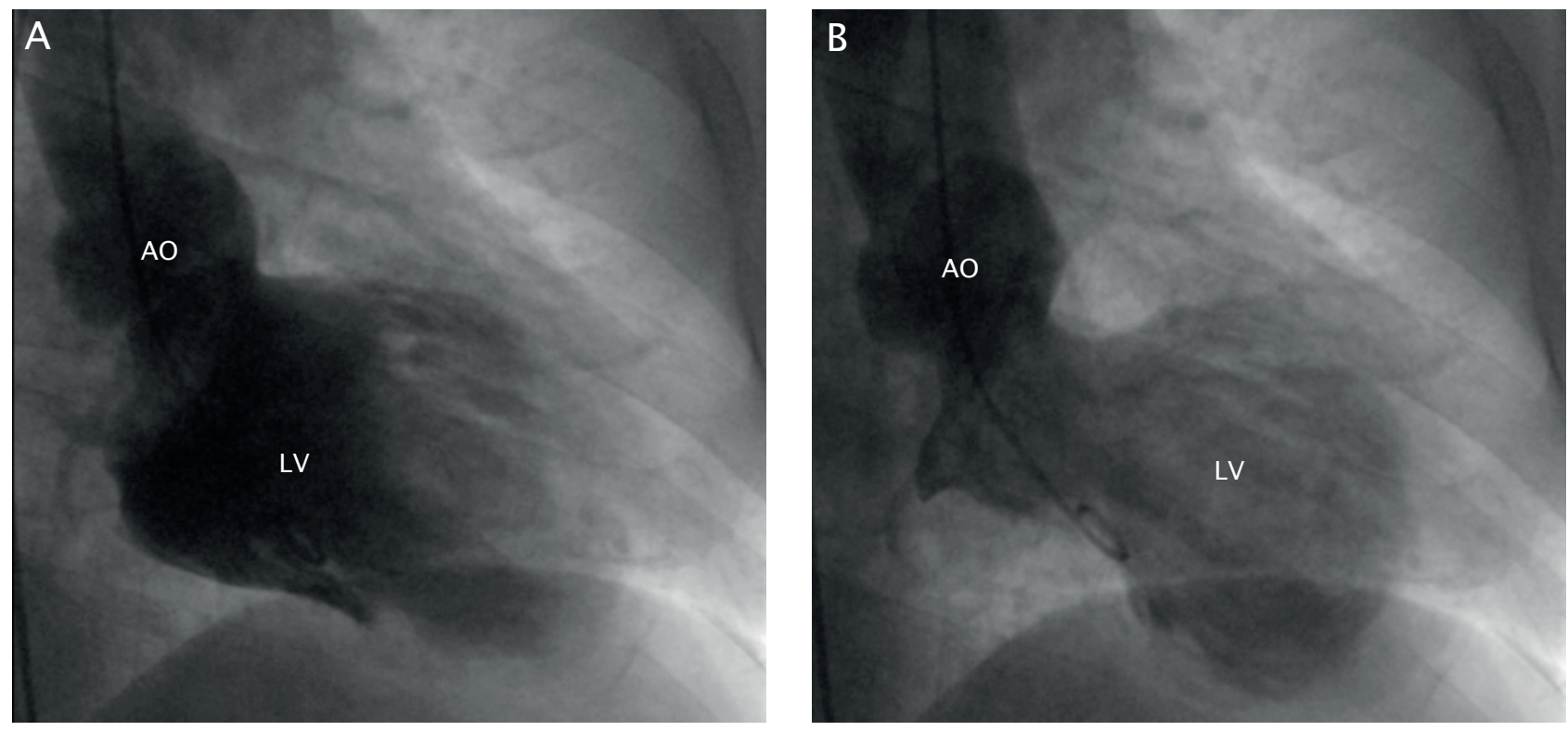

Fig. 3. Left ventriculography (A - diastolic, B - systolic): large dyskinesia of left ventricle apex and akinesia of anterior wall with severely impaired left ventricle systolic function with the ejection fraction of $25 \%$. Right anterior oblique $30^{\circ}$ projection. $\mathrm{AO}$, aorta; $\mathrm{LV}$, left ventricle.
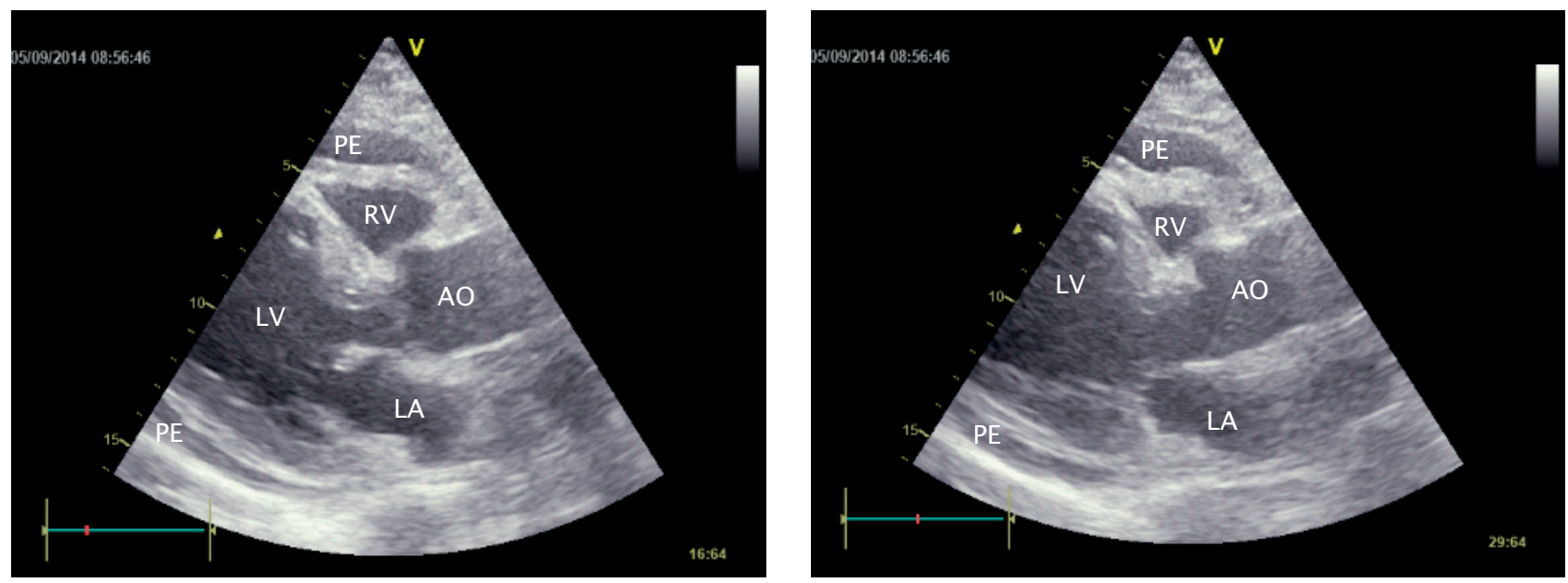

Fig. 4. Transthoracic echocardiographic images; still frames from parasternal long axis views (A - diastolic, B - systolic): severely impaired left ventricle systolic function with the estimated ejection fraction of $25 \%$, pericardial effusion. $\mathrm{AO}$, aorta; LA, left atrium; LV, left ventricle; PE, pericardial effusion; RV, right ventricle.

cardiologist and perfusionist arrived at our hospital within 40 min and venoarterial ECMO was implanted emergently in the catheterization laboratory using femoro-femoral access. The distal-perfusion cannula was utilized in order to prevent limb ischemia. The patient remained awake during the whole procedure (an awake ECMO approach), the circulation improved with the possibility to reduce and subsequently withdraw the inotropes. The anticoagulation with unfractionated heparin (UFH) was initiated according to the anticoagulation protocol of ELSO centre with the target value of activated partial thromboplastin time (APTT) of 45-60 s (heparin coated ECMO circuit). We considered this consecution as a bridge to decision (BTD) - a decision whether the myocardial function would recover or not and the patient was transferred to the ELSO centre.
On the third day of hospitalization, the patient became suddenly severely hemodynamically unstable, necessitating mechanical ventilation and vasoactive drug therapy. The echocardiography revealed cardiac tamponade and emergent surgical intervention was indicated. The heart was approached through a sternotomy and $600 \mathrm{~mL}$ of pericardial clots and blood were evacuated from the pericardium. The covered left ventricular free wall rupture (LVFWR) was detected in the absence of source of active bleeding. Subsequently, the patient's hemodynamic status improved rapidly with no further need for inotropic support.

Anticoagulation treatment with UFH was continued and tightly controlled by APTT values. Mechanical ventilation was withdrawn on the fifth day of hospitalization and patients remained awake on ECMO. Despite repeated 
Table 1. Patient's available laboratory parameters.

\begin{tabular}{|c|c|c|c|c|c|c|}
\hline Test/Parameter & $\begin{array}{l}\text { Reference } \\
\text { range }\end{array}$ & $\begin{array}{c}\text { On } \\
\text { admission }\end{array}$ & $\begin{array}{c}\text { Before } \\
\text { ECMO } \\
\text { implantation } \\
\left(2^{\text {nd }} \text { day after ACS }\right) \\
\end{array}$ & $\begin{array}{c}\text { Before } \\
\text { LVAD } \\
\text { implantation } \\
\left(10^{\text {th }} \text { day after } \mathrm{ACS}\right)\end{array}$ & $\begin{array}{c}\text { On } \\
\text { discharge } \\
\left(97^{\text {th }} \text { day }\right. \\
\text { after ACS })\end{array}$ & $\begin{array}{c}\text { Outpatient } \\
\text { medical check-up } \\
\left(111^{\text {th }} \text { day }\right. \\
\text { after ACS })\end{array}$ \\
\hline \multicolumn{7}{|l|}{ Chemistry } \\
\hline Sodium & $135-145 \mathrm{mmol} / \mathrm{L}$ & 139 & 143 & 141 & 133.3 & 131.7 \\
\hline Potassium & $3.5-5.0 \mathrm{mmol} / \mathrm{L}$ & 3.8 & 4.6 & 4.7 & 4.41 & 3.93 \\
\hline Chloride & 95-105 mmol/L & 103 & 105 & 96 & 101 & 99.2 \\
\hline Creatinine & $64-104 \mu \mathrm{mol} / \mathrm{L}$ & 90 & 138 & 100 & 72.6 & 77.9 \\
\hline BUN & $3-9.2 \mathrm{mmol} / \mathrm{L}$ & 5.3 & 10 & 17.1 & 3.3 & 4.3 \\
\hline Troponin I & $<0.1 \mu \mathrm{g} / \mathrm{L}$ & 48.135 & 205.657 & & & \\
\hline hs-Troponin T & $<35 \mathrm{ng} / \mathrm{L}$ & & & 3070 & & \\
\hline AST & $0.17-0.75 \mu \mathrm{kat} / \mathrm{L}$ & 5.31 & 10.77 & 3.03 & 0.36 & 0.35 \\
\hline ALT & $0.17-1.17 \mathrm{mmol} / \mathrm{L}$ & 1.07 & 2.24 & 9.67 & 0.42 & 0.44 \\
\hline CRP & $<5 \mathrm{mg} / \mathrm{L}$ & 3.7 & 113.4 & 125.9 & 133.7 & 37.5 \\
\hline Glucose & $3.6-5.6 \mathrm{mmol} / \mathrm{L}$ & 8.2 & 6.9 & 5.3 & 5.54 & 6.35 \\
\hline Lactate & $0.5-2.0 \mathrm{mmol} / \mathrm{L}$ & & 2.3 & 0.8 & 1.2 & \\
\hline BNP & $10-80 \mathrm{ng} / \mathrm{L}$ & & 373 & 1584.3 & 124 & 167 \\
\hline \multicolumn{7}{|l|}{ Hematology } \\
\hline WBC count & $4-10 \times 10^{9} / \mathrm{L}$ & 9.8 & 15.2 & 10.5 & 8.3 & 7.8 \\
\hline RBC count & $4.3-5.4 \times 10^{12} / \mathrm{L}$ & 4.5 & 4.4 & 3.21 & 3.87 & 4.38 \\
\hline Platelet count & $150-400 \times 10^{9} / \mathrm{L}$ & 224 & 201 & 70 & 278 & 385 \\
\hline Hemoglobin & $130-170 \mathrm{~g} / \mathrm{L}$ & 156 & 151 & 99 & 116 & 125 \\
\hline Hematocrit & $40 \%-52 \%$ & 47 & 44 & 29 & 34 & 37 \\
\hline MCV & $80-100 \mathrm{fL}$ & 100 & 100 & 93.4 & 87.6 & \\
\hline \multicolumn{7}{|l|}{ Coagulation } \\
\hline INR & $0.8-1.2$ & & 1.29 & 1.38 & 2.56 & 3.04 \\
\hline APTT & $20-40 \mathrm{sec}$ & & 180 & 60.7 & & \\
\hline Antithrombin III & $80-120 \%$ & & 73 & 61 & & \\
\hline D-dimer & $<250 \mathrm{ng} / \mathrm{mL}$ & & 386 & 6538 & 374 & \\
\hline \multicolumn{7}{|l|}{ Arterial blood gas } \\
\hline $\mathrm{pH}$ & $7.35-7.45$ & & 7.324 & 7.581 & & \\
\hline Base excess & $-2-+2 \mathrm{mEq}$ & & -5.6 & +2.3 & & \\
\hline $\mathrm{pO} 2$ & $9.9-13.5 \mathrm{kPa}$ & & 7.3 & 9.2 & & \\
\hline $\mathrm{pCO} 2$ & $4.7-6 \mathrm{kPa}$ & & 4.86 & 5.19 & & \\
\hline Oxygen saturation & $94-99 \%$ & & 86 & 97.5 & & \\
\hline Actual bicarbonate & $22-26 \mathrm{mmol} / \mathrm{L}$ & & 19.1 & 26.2 & & \\
\hline
\end{tabular}

ACS, acute coronary syndrome; ALT, alanine aminotransferase; APTT, activated partial thromboplastin time; AST, aspartate aminotransferase; ALT, alanine aminotransferase; BNP, B-type natriuretic peptide; BUN, blood urea nitrogen; CRP, C-reactive protein; INR, international normalized ratio; $\mathrm{MCV}$, mean corpuscular volume; $\mathrm{pH}$, potential of hydrogen; $\mathrm{pCO}$, partial pressure of carbon dioxide; $\mathrm{pO}$, partial pressure of oxygen; $\mathrm{RBC}$, red blood cell; WBC, white blood cell

attempts during the fifth to the eighth day, the patient could not be weaned from ECMO. His blood tests during this period of time showed transient impairment of renal and liver function in relation to MOF. Other laboratory data were indicative for incipient, non-symptomatic type of disseminated intravascular coagulation (DIC) as a result of "ECMO coagulopathy" and systemic inflammatory response. Arterial blood gas showed metabolic alkalosis with hypernatremia. The treatment of aforementioned abnormalities was focused on the proper management of underlying disease. The results of the latest laboratory tests carried out in ELSO centre are shown in Table 1 (see section "before LVAD implantation"). Further echocardiographic evaluation of left ventricular systolic function showed extremely low ejection fraction below $20 \%$ and spontaneous cardiac output (LCO) of approximately 1.4 $\mathrm{L}$ per minute. Since no chance for recovery of myocardial function was anticipated, the implantation of a left ventricular assist device (LVAD) was discussed with the transplant centre, where the patient was subsequently transferred. This step was also backed by worries of possible complications associated with ongoing ECMO support. However, the complications did not occur with the exception of aforementioned blood coagulation disorder.

Heart Mate II was implanted on the ninth day of hospitalization as a bridge to transplant (BTT). The surgical procedure included the removal of intracardiac thrombus within the apex of the left ventricle and the fixation of the inflow cannula with a pericardial patch and biological glue, as it was placed in the site of necrotic myocar- 
dium stemming from the previous infarction. A reason for chronic LVAD instead of short-term LVAD cannulated via left atrium have been two pronged: need for a removal of semi malignant thrombus out of the left ventricle and unstable contained rupture of left ventricular free wall with a high potential of late bleeding without reinforcement. After the Heart Mate II was implanted, the temporary circulatory support with inotropes (milrinon and dobutamin) was necessary. Anticoagulation with warfarin was initiated and the treatment with heparin was withdrawn as the effective value of international normalized ratio was achieved. The patient's further recovery was complicated by Clostridium Difficile infection, which was successfully treated with metronidazole and vancomycin. Subsequently, he was placed on the heart transplant waiting list. The patient was discharged two months after LVAD implantation. The laboratory results at the discharge were satisfactory (see Table 1). He appeared well on the first outpatient medical examination 14 days after his discharge from the hospital and his brain natriuretic peptide levels were almost within the normal range (see Table 1).

\section{DISCUSSION}

When cardiogenic shock, the most severe form of acute heart failure, appears in the context of STEMI, the only approach that reduces both short-term and long-term mortality significantly, is the emergent coronary revascularization ${ }^{1,5}$. The European Society of Cardiology (ESC) and European Association for Cardio-Thoracic Surgery (EACTS) recommends emergent reperfusion by means of PCI or coronary artery bypass grafting (CABG) as a class $\mathrm{I} / \mathrm{B}$ in this setting ${ }^{6}$. In spite of the above mentioned facts and other advances in the management of CSMI mortality remains around $50 \%$, which is less compared to conservative treatment ( $70 \%$ to $80 \%$ ), however, still remains high $^{7-9}$.

When circulatory blood volume is normal and blood pressure remains unacceptably low due to LCO caused by depressed contractility of myocardium, the vasoactive drugs such as inotropes and vasopressors are used to improve the circulation and the tissue perfusion. However, these drugs can cause arrhythmia and deepen myocardial ischemia. Moreover, impact on mortality in this group of patients remains controversial ${ }^{10}$. When pharmacological treatment fails to maintain the adequate MAP and endorgan perfusion or when inotropes-related complications occur such as ventricular fibrillation in our case, the initiation of short-term MCS should be considered. Intraaortic balloon pump counterpulsation (IABP) is widely available in PCI centres, however, recent data challenged the beneficial impact of IABP on reducing mortality in CSMI patients compared to a standard medical therapy. Therefore, 2014 ESC/EATS guidelines on myocardial revascularization state that "Routine use of IABP in patients with cardiogenic shock is not recommended" (ref. ${ }^{6,11,12}$ ). However, it is still being used despite current controversy.

The purpose of MCS initiation is the prevention of
MOF, stabilization of end organ function and allowing spontaneous recovery of affected organs. Thus, it can save time in order to decide on further action or considering the use of a long-term support system or indications for organ transplantation ${ }^{13}$. Considering other devices for circulatory support, ECMO appears to be most useful in the setting of RCSMI since it provides the full circulatory support, the percutaneous insertion of cannulas is quick and relatively easy and it improves end-organ perfusion. However, there is a lack of meta-analysis and randomized clinical trials proving the positive impact of ECMO on clinical outcome in the patients with RCSMI (ref. ${ }^{14}$ ). Furthermore, despite the adequate density of PCI capable hospitals in the Czech Republic, ECMO is only available in a few specialized centres. Nevertheless, the availability of a mobile ECMO transport team allows the use of this method even in hospitals without on-site surgical facilities $^{15}$. The collaboration with an efficiently organized ELSO centre and a properly defined ECMO team role is essential.

It is necessary to define the goal to achieve while using short-term MCS in the setting of RCSMI: 1/BTD - obtaining the time for evaluating and considering further strategy, 2/a bridge to recovery (BTR) - providing the time for the recovery of reversible dysfunctional myocardium, 3/a bridge to device - a bridge to long-term MCS if the weaning from short-term MCS is not successful, 4/a bridge to further intervention - such as PCI or cardiac surgery and 5/a bridge to transplant (BTT) (ref. ${ }^{16}$ ). The latter is, however, very rare in the setting of short-term MCS due to a shortage of donor organs ${ }^{4}$. Regarding our patient, ECMO was implanted due to a severe left ventricle dysfunction resulting in MOF. This was primarily taken as BTR, nevertheless, we anticipated the difficult myocardial recovery due to TIT of 11 hours, since this period is probably the most important factor in the context of myocardial recovery ${ }^{6}$. Simultaneously, prolonged TIT along with other present features such as the first transmural infarction, no previous angina and the absence of collateral vessels are the risk factors for the LVFWR as a complication of acute myocardial infarction, which is the second most common cause of death next to cardiogenic shock in this setting ${ }^{17}$. In one out of three patients, this mechanical cause of heart failure has a subacute course, which gains time for emergency surgery as a treatment of choice. In our case, ECMO support provided also the bridge to surgery, although it had already been implanted for another reason ${ }^{18}$. During this decision making process, awake ECMO approach is an optimal way to consult the further course of treatment with the patient and to incorporate him into the multidisciplinary team dealing with such a severe clinical condition.

The optimal duration of short-term MCS in RCSMI is not well defined yet and the decision, whether to discontinue the MCS, depends on meeting the conditions of recovery ${ }^{19}$. Our patient was not able to be weaned after six days of ECMO support, therefore, it was decided to implant LVAD. Nonetheless, generally, the reason to withdraw ECMO with the transition to LVAD is not only the very low chance of myocardial recovery based on the TTE 
and clinical findings. It is also the awareness of increasing risk of occurrence of complications with the extension of the length of this treatment. The most common complications of ECMO are bleeding, limb ischemia, thrombosis of ECMO system, left ventricle overload and "Harlequin syndrome" (hypoxia of the head and upper extremities) $\left(\right.$ ref. $\left.{ }^{16}\right)$. In our case, the heparin coated ECMO system was used in order to prevent bleeding complications, since the lower levels of APTT were required. The utilization of distal-perfusion cannula reduces the probability of the lower limb ischemia. The pathogenesis of coagulation disorders associated with ECMO is multifactorial. Foreign surface of ECMO circuit can play the key role in the development of DIC, nevertheless, there are other causative circumstances in patients in such critical condition. Careful coagulation monitoring is inseparable aspect of ECMO management ${ }^{20}$. Generally, a thorough clinical observation and repeated inspections of ECMO circuit are absolutely essential.

The recommendations for LVAD therapy are based on the ESC guidelines published in 2012 (ref. ${ }^{10}$ ). In our case, the patient was at the risk of immediate death from non-reversible left ventricular failure without MCS. The HeartMate II Left Ventricular Assist System was implanted in the lowest INTERMACS level 1. The left ventricle thrombus can cause serious dysfunction of LVAD and therefore it should be solved simultaneously. There is, however, little information on this topic in the literature ${ }^{21}$. Our patient met the criteria for HTX, the indication for the LVAD treatment was considered as BTT. Nevertheless, the patient can become ineligible for HTX over the course of time and then the intention should be reconsidered to either bridge to candidacy or destination therapy ${ }^{22}$. Also, the lack of donor organs and the growing incidence of heart failure is another serious problem in this context ${ }^{23}$.

\section{CONCLUSION}

The interhospital collaboration can play the key role in the context of patients with RCSMI. The majority of these patients with or without already expressed heart failure initially present to the community hospital without PCI facilities ${ }^{19}$. The primary PCI should be carried out as soon as possible in one of the PCI centres, of which density is adequate concerning the conditions in the Czech Republic ${ }^{24}$. Not every hospital performing PCI in the Czech Republic is able to provide appropriate MCS in RCSMI. Then, emergently available mobile ECMO transport team is essential. It is necessary to emphasize the importance of proper indication and timing of each step, namely well-timed initiation of ECMO to prevent the development of MOF and after initial stabilization, the patients with the inability to be weaned should be assessed for transition to LVAD, avoiding inappropriate delay. An awake ECMO approach in this setting represents a unique way to keep the patient in being an active participant in this decision making process.

\section{ABBREVATIONS}

ACS, acute coronary syndrome; APTT, activated partial thromboplastin time; BTD, bridge to decision; BTR, bridge to recovery; BTT, bridge to transplantation; CSMI, cardiogenic shock as a complication of acute myocardial infarction; DIC, disseminated intravascular coagulopathy; EACTS, European Association for Cardio-Thoracic Surgery; ECMO, extracorporeal membrane oxygenation; EF, ejection fraction; ELSO, Extracorporeal Life Support Organization; ESC, European Society of Cardiology; HTX, heart transplantation; IABP, Intra-aortic balloon pump counterpulsation; LAD, left anterior descending coronary artery; LCO, low cardiac output; LV, left ventricle; LVAD, left ventricle assist device; LVFWR, left ventricle free wall rupture; LVG, left ventriculography; MAP, mean arterial pressure; MCS, mechanical circulatory support, MOF, multiorgan failure; PCI, percutaneous coronary intervention; RCSMI, refractory cardiogenic shock as a complication of acute myocardial infarction; STEMI, ST-elevation myocardial infarction; TIT, total ischemic time; TTE, transthoracic echocardiography; $\mathrm{UFH}$, unfractionated heparin.

Acknowledgement: The study was supported by project "Pulmonary circulation and hemodynamics", reg.no. CZ.2.16/3.1.00/21565 from OP Prague Competitiveness and partially by a research grant from Internal Grant Agency Ministry of Health, Czech Republic NT 132254/2012.

Written informed consent was obtained from the patient for publication of this case report and any accompanying images. A copy of the written consent is available for review at the author of this manuscript.

Author contributions: JK, ML, JB: manuscript design; RS, IN, FM, TG: final approval.

Conflict of interest statement: The authors state that there are no conflicts of interest regarding the publication of this article.

\section{REFERENCES}

1. Hochman JS, Sleeper LA, Webb JG, Sanborn TA, White HD, Talley JD, Buller CE, Jacobs_AK, Slater JN, Col J, McKinlay SM, LeJemtel TH. SHOCK Investigators. Early revascularization in acute myocardial infarction complicated by cardiogenic shock. Should We Emergently Revascularize Occluded Coronaries for Cardiogenic Shock. N Engl J Med 1999;341:625-34.

2. Westaby S, Anastasiadis K, Wieselthaler GM. Cardiogenic shock in ACS. Part 2: role of mechanical circulatory support. Nat Rev Cardiol 2012;9:195-208.

3. Takayama H, Truby L, Koekort M, Uriel N, Colombo P, Mancini DM, Jorde UP, Naka Y. Clinical outcome of mechanical support for refractory cardiogenic shock in the current era. J Heart Lung Transplant 2013;32:106-11.

4. Brugts JJ, Manintveld O, Constantinescu A, Donker DW, van Thiel RJ, Nieman K, Jewbali LS, Zijlstra F, Caliskan K. Preventing LVAD implantation by early short-term mechanical support and prolonged inodilator therapy: A case series with acute refractory cardiogenic shock treated with veno-arterial extracorporeal membrane oxygenation and optimised medical strategy. Netherlands Heart Journal 2014;22(4):176-81.

5. Hochman JS, Sleeper LA, Webb JG, Dzavik V, Buller CE, Aylward P, Col 
J, White HD; SHOCK Investigators. Early Revascularization Improves Long-Term Survival for Cardiogenic Shock Complicating Acute Myocardial Infarction. JAMA : the journal of the American Medical Association 2006;295(21):2511-5.

6. Windecker S, Kolh P, Alfonso F, Collet JP, Cremer J, Falk V, Filippatos G, Hamm C, Head SJ, Jüni P, Kappetein AP, Kastrati A, Knuuti J, Landmesser U, Laufer G, Neumann FJ, Richter DJ, Schauerte $P_{\text {}}$ Sousa Uva M, Stefanini GG, Taggart DP, Torracca L, Valgimigli M, Wijns W, Witkowski A. 2014 ESC/EACTS Guidelines on myocardia revascularization: The Task Force on Myocardial Revascularization of the European Society of Cardiology (ESC) and the European Association for Cardio-Thoracic Surgery (EACTS) Developed with the special contribution of the European Association of Percutaneous Cardiovascular Interventions (EAPCI) Eur Heart J 2014;46(4):517-92.

7. Goldberg RJ, Spencer FA, Gore JM, Lessard D, Yarzebski J. Thirty Year Trends (1975-2005) in the Magnitude, Management, and Hospita Death Rates Associated With Cardiogenic Shock in Patients with Acute Myocardial Infarction: A Population-Based Perspective. Circulation 2009;119(9):1211-9.

8. Kolte D, Khera S, Aronow WS, Mujib M, Palaniswamy C, Sule S, Jain D, Gotsis W, Ahmed A, Frishman WH, Fonarow GC. Trends in Incidence, Management, and Outcomes of Cardiogenic Shock Complicating ST-Elevation Myocardial Infarction in the United States. Journal of the American Heart Association: Cardiovascular and Cerebrovascular Disease 2014;3(1):e000590.

9. Goldberg RJ, Gore JM, Thompson CA, Gurwitz JH. Recent magnitude of and temporal trends (1994-1997) in the incidence and hospital death rates of cardiogenic shock complicating acute myocardial infarction: the second national registry of myocardial infarction. Am Heart J 2001;141:65-72.

10. The Task Force for the Diagnosis, Treatment of Acute, Chronic Heart Failure 2012 of the European Society of Cardiology. Developed in collaboration with the Heart Failure Association (HFA) of the ESC. ESC Guidelines for the diagnosis and treatment of acute and chronic heart failure 2012. Eur Heart J 2012;33:1787-1847.

11. Thiele H, Zeymer U, Neumann F, Ferenc M, Olbrich $H$, Hausleiter J, Richardt G, Hennersdorf M, Empen K, Fuernau G, Desch S, Eitel I, Hambrecht R, Fuhrmann J, Böhm M, Ebelt H, Schneider S, Schuler $\mathrm{G}$, Werdan K. Intraaortic balloon support for myocardial infarction with cardiogenic shock. N Engl J Med 2012;367:1287-96.

12. Thiele $H$, Zeymer $U$, Neumann F, Ferenc M, Olbrich $H$, Hausleiter J Waha A de, Richardt G, Hennersdorf M, Empen K, Fuernau G, Desch S, Eitel I, Hambrecht R, Lauer B, Böhm M, Ebelt H, Schneider S, Werdan $\mathrm{K}$, Schuler G. Intra-aortic balloon counterpulsation in acute myocardial infarction complicated by cardiogenic shock (IABP-SHOCK
II): final 12 month results of a randomised, open-label trial. Lancet 2013;382:1638-45.

13. Bělohlávek J, Rohn V, Kunstýř J, Tošovský J, Balík $M$, Semrád $M$ Horák J, Lipš M, Romaniv S, Mlejnský F, Vykydal I, Krištof J, Stříteský M, Mrázek V, Linhart A, Lindner J. A profile of patients treated by extracorporeal membrane oxygenation (ECMO). Interv Akut Kardiol 2010;9:121-8.

14. Karl Werdan, Stephan Gielen, Henning Ebelt, Judith S. Hochman Mechanical circulatory support in cardiogenic shock, European Heart Journal Jan 2014,35(3)156-167.

15. Belle L, Mangin L, Bonnet $H$, Fol S, Santré C, Delavenat L, Savary D, Bougon D, Vialle E, Dompnier A, Desjoyaux E, Blin D. Emergency extracorporeal membrane oxygenation in a hospital without on-site cardiac surgical facilities. Eurolntervention 2012;8(3):375-82.

16. Oštádal P, Bělohlávek J. ECMO - extrakorporální membránová oxygenace Praha: Maxdorf, 2013.

17. Braunwald $E$, Bonow RO. Braunwald's heart disease: a textbook of cardiovascular medicine 9th ed. Philadelphia: Saunders, 2012.

18. Amir O, Smith R, Nishikawa A, Gregoric ID, Smart FW. Left Ventricular Free Wall Rupture in Acute Myocardial Infarction: A Case Report and Literature Review. Texas Heart Institute Journal 2005;32(3):424-6.

19. Kar B, Gregoric ID, Basra SS, Idelchik GM, Loyalka P. The percutaneous ventricular assist device in severe refractory cardiogenic shock. J Am Coll Cardiol 2011;57:688-96.

20. Guillermo M, Alain V. Extracorporeal Membrane Oxygenation in Adults. Cont Edu Anaesth Crit Care and Pain 2012;12(2):57-61.

21. Cousin E, Scholfield M, Faber C, Caldeira C, Guglin M. Treatment options for patients with mobile left ventricular thrombus and ventricular dysfunction: a case series. Heart, Lung and Vessels 2014;6(2):88-91.

22. Teuteberg JJ, Stewart GC, Jessup M, Kormos RL, Sun B, Frazier OH, Naftel DC, Stevenson LW. Implant strategies change over time and impact outcomes: insights from the INTERMACS (Interagency Registry for Mechanically Assisted Circulatory Support). JACC Heart Fail 2013;1:369-78.

23. Puehler T, Ensminger S, Schoenbrodt M, Börgermann J, Rehn $E$ Hakim-Meibodi K, Morshuis M, Gummert J. Mechanical circulatory support devices as destination therapy-current evidence. Annals of Cardiothoracic Surgery 2014;3(5):513-24.

24. Widimský $P$, Budesínský $T$, Vorác D, Groch L, Zelizko M, Aschermann M, Branny M, St'asek J, Formanek P, PRAGUE Study Group Investigators Long distance transport for primary angioplasty vs immediate thrombolysis in acute myocardial infarction. Final results of the randomized national multicentre trial - PRAGUE-2. Eur Heart J 2003:24:94-104. 